\title{
Metformin Association with Lower Prostate Cancer Recurrence in Type 2 Diabetes: a Systematic Review and Meta-analysis
}

\author{
In Cheol Hwang', Sang Min Park ${ }^{2 *}$, Doosup Shin ${ }^{3}$, Hong Yup Ahn ${ }^{4}$, Malte \\ Rieken $^{5}$, Shahrokh F Shariat ${ }^{6}$
}

\begin{abstract}
Background: Accumulating evidence suggests that metformin possesses anticarcinogenic properties, and its use is associated with favorable outcomes in several cancers. However, it remains unclear whether metformin influences prognosis in prostate cancer (PCa) with concurrent type 2 diabetes (T2D). Materials and Methods: We searched PubMed, EMBASE, and the Cochrane Library from database inception to April 16, 2014 without language restrictions to identify studies investigating the effect of metformin treatment on outcomes of PCa with concurrent T2D. We conducted a meta-analysis to quantify the risk of recurrence, progression, cancer-specific mortality, and all-cause mortality. Summary relative risks (RRs) with corresponding 95\% confidence intervals (CIs) were calculated. Publication bias was assessed by Begg's rank correlation test. Results: A total of eight studies fulfilled the eligibility criteria. We found that diabetic PCa patients who did not use metformin were at increased risk of cancer recurrence (RR, 1.20; 95\% CI, 1.00-1.44), compared with those who used metformin. A similar trend was observed for other outcomes, but their relationships did not reach statistical significance. Funnel plot asymmetry was not observed among studies reporting recurrence $(p=0.086)$. Conclusions: Our results suggest that metformin may improve outcomes in PCa patients with concurrent T2D. Well-designed large studies and collaborative basic research are warranted.
\end{abstract}

Keywords: Diabetes - metformin - prognosis - prostate cancer

Asian Pac J Cancer Prev, 16 (2), 595-600

\section{Introduction}

The effect of metformin use on outcomes of diabetic prostate cancer $(\mathrm{PCa})$ remains unclear, whereas a reduced incidence of PCa has been reported in subjects with type 2 diabetes (T2D) (Bansal et al., 2013). The latest metaanalysis reported that metformin use was associated with a reduced risk of cancer-specific mortality (CSM)/ all-cause mortality (ACM) in diabetic PCa patients, but it did not reach statistical significance (Zhang and Li, 2014). Other than survival, the results of studies on other clinical endpoints of PCa such as biochemical recurrence or systemic progression have been inconsistent (Spratt et al., 2013; Kaushik et al., 2014; Rieken et al., 2014).

Metformin, which is the most widely prescribed antidiabetic drug, has shown excellent tolerability and efficacy. Metformin use is associated with favorable outcomes in cancer through its ability to indirectly modulate insulin levels, which can affect tumor growth (Pollak, 2008). In addition, metformin appears to inhibit tumor initiation or progression (Emami Riedmaier et al., 2013). This effect is thought to be mediated through the protein kinase B (Akt)-mammalian target of rapamycin (mTOR) pathway following 5' adenosine monophosphateactivated protein kinase activation: Akt plays a crucial role in multiple cellular processes, and mTOR regulates protein translation, cell growth, and apoptosis (Pollak, 2012). Alterations in the pathway regulating mTOR are found in many solid tumors including PCas (Garcia and Danielpour, 2008). PCas continue to comprise a considerable proportion of incident and prevalent cancer cases. Because of their nature and long-term survival for patients, the potential influence of modifiable conditions on PCa outcomes warrants investigation.

Despite the evidences for a potential protective effect of metformin on PCa (Ben Sahra et al., 2008) and other malignancies (Landman et al., 2010), the role of metformin on PCa outcomes remains controversial. Results from previous studies have been conflicting due to heterogeneity of study design, diverse outcome measures and small sample sizes. Furthermore, some studies evaluating the effect of metformin on cancer outcomes use non-diabetics or non-users (regardless of T2D) as the comparison group (Niraula et al., 2013;

${ }^{1}$ Department of Family Medicine, Gachon University Gil Medical Center, Incheon, ${ }^{2}$ Department of Family Medicine and Biomedical Sciences, ${ }^{3}$ Department of Education and Research, Seoul National University College of Medicine; ${ }^{4}$ Department of Statistics, Dongguk University, Seoul, Korea, ${ }^{5}$ Department of Urology, University Hospital Basel, Basel, Switzerland, ${ }^{6}$ Department of Urology, Medical University of Vienna, Vienna, Austria*For correspondence: smpark.snuh@gmail.com 
In Cheol Hwang et al

Rieken et al., 2014), rather than diabetic non-users of metformin. Because diabetes itself is associated with worse PCa outcomes (Snyder et al., 2010), it is difficult to differentiate the effect of T2D from metformin exposure and translate study results into clinical practice. For that reason, we performed a comprehensive meta-analysis of currently available relevant studies to quantify the effect of metformin use on various PCa outcomes among patients with T2D.

\section{Materials and Methods}

\section{Information sources and search strategy}

We searched PubMed, EMBASE, and the Cochrane Library from database inception to April 16, 2014 without language restrictions. Search terms were related to metformin (metformin, biguanides), cancer (cancer, neoplasm, tumor), and outcomes (prognosis, mortality, survival, recurrence). A manual review of references from primary and review articles was performed to identify any other relevant studies that were not captured through the initial database searches. Our systematic review followed the guidelines for meta-analysis of observational studies in epidemiology (Stroup et al., 2000).

\section{Study selection and eligibility criteria}

We selected observational studies that investigated relationships between metformin use and cancer-related outcomes in diabetic patients with PCas. We primarily excluded reviews, case reports, and non-peer reviewed sources (e.g., author replies, conference abstracts). To be included in the meta-analysis, the studies had to provide a risk estimate (e.g., hazard ratio, relative risk [RR], odds ratio) and measure of precision (e.g., confidence interval [CI]) for the impact of metformin use on outcomes (recurrence, progression, CSM, or ACM). We excluded data on castration-resistant $\mathrm{PCa}$, which was reported by only one paper (Spratt et al., 2013). We collected the fully adjusted risk estimates. In case of multiple publications based on the same study population, the most recent publication and/or the study with largest number of cases was included in the analysis.

\section{Data extraction}

All potentially relevant articles were independently evaluated by two investigators (IC Hwang and D Shin); disagreements were resolved by consensus or consultation with a third author (SM Park). The following data were abstracted from each study: first author, year of publication, country, study design, site of cancer, clinical setting, study period, length of follow-up, number of patients in each group, outcome assessed, risk estimates with corresponding 95\% CIs, and variables adjusted. We used the Newcastle-Ottawa Scale (NOS) to assess the methodological quality. Low quality was defined as NOS score $\leq 8.0$, and high quality as NOS score $>8.0$ (maximum score, 9).

\section{Main and subgroup analyses}

We investigated the relationship between metformin use and the risk of four outcomes (recurrence, progression,
CSM, and ACM) of PCa patients with T2D. With regards to recurrence and ACM, we performed a subgroup metaanalysis based on study design (cohort study or nested case-control) or methodological quality of the study (high or low); there were insufficient data to conduct sub-analyses of other characteristics.

\section{Statistical analysis}

We calculated a pooled RR with $95 \%$ CI from those reported in individual studies. To calculate the variance of the $\log$ RR from each study, we converted the $95 \% \mathrm{CI}$ to its natural logarithm by taking the width of the CI and dividing by 3.92. Summary RR estimates were derived using the method of DerSimonian and Laird (DerSimonian and Laird, 1986).

To test heterogeneity, we used Higgins $I^{2}$, which indicates the percentage of variation across studies. $I^{2}$ ranged from $0 \%$ to $100 \%$, where $I^{2}>50 \%$ indicates significant heterogeneity, and $I^{2}<25 \%$ indicates insignificant heterogeneity (Higgins and Thompson, 2002). When substantial heterogeneity was observed, we used the DerSimonian and Laird random-effects model, which is the generally preferred approach (DerSimonian and Laird, 1986). We used inverse-variance weighting to calculate fixed- and random-effects summary estimates. Publication bias was assessed using the Begg's rank correlation test (Begg and Mazumdar, 1994). All statistical analyses were performed with Stata version 12.1 (StataCorp, College Station, TX, USA).

\section{Results}

\section{Study selection and characteristics}

Figure 1 shows a flow diagram for the identification of relevant studies. Of the 1,464 non-duplicate titles reviewed, 626 were included in the abstract review, and 46 of those studies met our eligible criteria. After reviewing the full text of the remaining articles, we excluded 35 articles for the following reasons: no information regarding metformin use $(n=17)$, reported only incidence data $(n=8)$, addressed the effect of metformin use in other cancers but not in PCa specifically $(n=9)$, no specific data for diabetic non-users of metformin $(n=2)$, and were

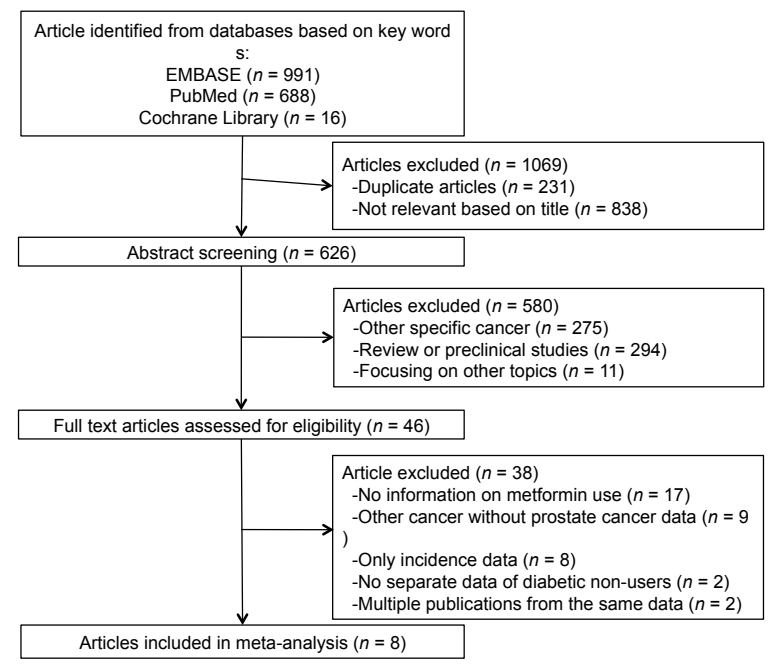

Figure 1. Flow Diagram for Identification of Relevant Articles 
multiple publications based on the same data $(n=2)$. The remaining eight studies were included in the final analysis.

Characteristics of the included studies (four cohort studies and four nested case-control studies) are summarized in Table 1. All studies were published in the past 5 years and were limited to patients with PCas, with the exception of one study (Currie et al., 2012) that included patients with several types of cancer. Most of the studies were conducted in the United States $(n=5)(\mathrm{He}$ et al., 2011; Patel et al., 2010; Allott et al., 2013; Spratt et al., 2013; Kaushik et al., 2014), and the others were international multicenter studies $(n=1)$ (Rieken et al., 2014) or conducted in the United Kingdom $(n=1)$ (Currie et al., 2012) or Canada ( $n=1)$ (Margel et al., 2013). The mean NOS score for these eight studies was 8.38, and three studies were deemed to be high quality (Table 2). All of the studies adjusted for age, but adjustment for other covariates varied across studies. Progression was defined

Table 1. Characteristics of the Included Studies for the Impact of Metformin on Prostate Cancer Outcomes in Type 2 Diabetes

\begin{tabular}{|c|c|c|c|c|c|c|c|c|}
\hline Source & lountry & Design I & $\begin{array}{l}\text { Limited } \\
\text { stage }\end{array}$ & Period & $\begin{array}{l}\text { Follow } \\
\text { up }(y)\end{array}$ & $\begin{array}{c}\text { Outcomes } \\
\text { R/P/CSM/ACM }\end{array}$ & $\begin{array}{l}\text { No. of } \\
\text { cases/ } \\
\text { controls }\end{array}$ & Adjustments (other than age) \\
\hline \multicolumn{2}{|c|}{ Kaushik, 2014 USA } & $\begin{array}{c}\text { Nested } \\
\text { case-control }\end{array}$ & M0 & $1997-2010$ & 5.1 & yes/yes/no/yes & $323 / 562$ & $\begin{array}{l}\text { Obesity, Gleason score, } \\
\text { surgical margin, PSA, statin } \\
\text { use, adjuvant treatment }\end{array}$ \\
\hline Rieken, 2014 & International & Cohort & M0 & $2000-2011$ & 2.1 & yes/no/no/no & $287 / 377$ & $\begin{array}{l}\text { PSA, Gleason score, nodal } \\
\text { status, surgical margins, } \\
\text { extracapsular extension, } \\
\text { seminal vesicle invasion }\end{array}$ \\
\hline Spratt, 2013 & USA & Cohort & N0 & $1992-2008$ & 8.7 & yes/yes/yes/yes & $157 / 162$ & $\begin{array}{l}\text { Stage, Gleason score, PSA, } \\
\text { ADT }\end{array}$ \\
\hline Margel, 2013 & Canada & Cohort & All & 2004-2008 & 4.6 & no/no/yes/no & $1251 / 2586$ & $\begin{array}{l}\text { Gleason score, tumor volume, } \\
\text { ADT, surgery, radiotherapy, } \\
\text { comorbidity, residency, cohort } \\
\text { entry year, statin use, COX } \\
\text { inhibitor use }\end{array}$ \\
\hline Allot, 2013 & USA & $\begin{array}{c}\text { Nested } \\
\text { case-control }\end{array}$ & M0 & $1988-2010$ & 5.6 & yes/no/no/no & $155 / 214$ & $\begin{array}{l}\text { Surgery year, obesity, race, } \\
\text { PSA, surgical center, Gleason, } \\
\text { stage, extracapsular extension, } \\
\text { seminal vesicle invasion, } \\
\text { surgical margin }\end{array}$ \\
\hline Currie, 2012 & UK & Cohort & All & 1990-2009 & NR & no/no/no/yes & NR & $\begin{array}{l}\text { Sex, smoking, cancer duration, } \\
\text { Townsend index, comorbidi- } \\
\text { ties, general practice contacts }\end{array}$ \\
\hline He, 2011 & USA & $\begin{array}{c}\text { Nested } \\
\text { case-control }\end{array}$ & All & 1999-2008 & NR & no/no/no/yes & $132 / 101$ & $\begin{array}{l}\text { Race, Gleason score, stage, } \\
\text { obesity, other antidiabetic } \\
\text { use, PSA }\end{array}$ \\
\hline Patel, 2010 & USA & $\begin{array}{c}\text { Nested } \\
\text { case-control }\end{array}$ & M0 & 1990-2009 & NR & yes/no/no/no & $112 / 98$ & $\begin{array}{l}\text { Diabetes, PSA, Gleason score, } \\
\text { surgical margin, stage, race }\end{array}$ \\
\hline
\end{tabular}

*NR, not reported; R, recurrence; P, progression; CSM, cancer-specific mortality; ACM, all-cause mortality; PSA, prostate specific antigen; ADT, androgen deprivation therapy, COX, cyclooxygenase; GFR, glomerular filtration rate

Table 2. Methodological Quality of the Included Studies, As Assessed by the Newcastle-ottawa Scale

\begin{tabular}{|c|c|c|c|c|c|c|c|c|c|}
\hline & \multicolumn{3}{|c|}{ Selection } & \multicolumn{3}{|c|}{ Comparability } & \multicolumn{2}{|c|}{ Outcome } & \multirow{2}{*}{$\begin{array}{l}\text { Total } \\
\text { score } \\
(0-9)\end{array}$} \\
\hline & $\begin{array}{l}\text { Representati- } \\
\text { venessof } \\
\text { exposed cohort }\end{array}$ & $\begin{array}{l}\text { Selection of } \\
\text { non-exposed } \\
\text { rt cohort }\end{array}$ & $\begin{array}{l}\text { Ascertain- } \\
\text { ment of } \\
\text { exposure }\end{array}$ & $\begin{array}{l}\text { Presentation } \\
\text { of outcome } \\
\text { at start }\end{array}$ & $\begin{array}{l}\text { Control for } \\
\text { important } \\
\text { factor }\end{array}$ & $\begin{array}{l}\text { Assessment } \\
\text { of outcome }\end{array}$ & $\begin{array}{l}\text { Adequate } \\
\text { follow-up }\end{array}$ & $\begin{array}{l}\text { Adequate } \\
\text { follow-up }\end{array}$ & \\
\hline \multicolumn{10}{|l|}{ Cohort studies } \\
\hline Spratt, 2013 & 1 & 1 & 1 & 1 & 2 & 1 & 1 & 1 & 9 \\
\hline Rieken, 2013 & 1 & 1 & 1 & 1 & 2 & 1 & 1 & 1 & 9 \\
\hline Margel, 2013 & 1 & 1 & 1 & 1 & 2 & 1 & 1 & 1 & 9 \\
\hline \multirow[t]{3}{*}{ Currie, 2012} & 1 & 1 & 1 & 1 & 1 & 1 & 1 & 1 & 8 \\
\hline & \multicolumn{3}{|c|}{ Selection } & \multicolumn{3}{|c|}{ Comparability } & \multicolumn{2}{|c|}{ Exposure } & Total \\
\hline & $\begin{array}{l}\text { Adequate } \\
\text { definitionof } \\
\text { cases }\end{array}$ & $\begin{array}{l}\text { Representa- } \\
\text { tiveness } \\
\text { of cases }\end{array}$ & $\begin{array}{c}\text { Selection of } \\
\text { controls }\end{array}$ & \multicolumn{3}{|c|}{$\begin{array}{cc}\text { Definition of } & \text { Control for } \\
\text { control } & \text { Asc } \\
& \text { factor }\end{array}$} & $\begin{array}{l}\text { Same method } \\
\text { of ascertain- } \\
\text { ment }\end{array}$ & $\begin{array}{l}\text { Non-res- } \\
\text { ponse rate }\end{array}$ & $\begin{array}{l}\text { score } \\
(0-9)\end{array}$ \\
\hline \multicolumn{10}{|c|}{ Nested case-control } \\
\hline Kaushik, 2014 & 1 & 1 & 1 & 1 & 2 & 1 & 1 & 0 & 8 \\
\hline Allot, 2013 & 1 & 1 & 1 & 1 & 2 & 1 & 1 & 0 & 8 \\
\hline He, 2011 & 1 & 1 & 1 & 1 & 2 & 1 & 1 & 0 & 8 \\
\hline Patel, 2011 & 1 & 1 & 1 & 1 & 2 & 1 & 1 & 0 & 8 \\
\hline
\end{tabular}


Table 3. Subgroup Meta-analyses to Determine the Effect of Metformin Use on Recurrence and All-cause Mortality among Diabetic Prostate Cancer Patients

\begin{tabular}{|c|c|c|c|c|c|}
\hline Factor & & No. of studies & Summary RR (95\%CI) & Heterogeneity, $I^{2}$ & Model \\
\hline \multirow[t]{7}{*}{ Recurrence } & All & 5 & $1.20(1.00-1.44)$ & $24.50 \%$ & Fixed-effects \\
\hline & Study design & & & & \\
\hline & Cohort & 2 & $1.53(0.91-2.55)$ & $59.40 \%$ & Random-effects \\
\hline & Nested case-control & 3 & $1.09(0.87-1.35)$ & $0 \%$ & Fixed-effects \\
\hline & Quality of study & & & & \\
\hline & Low & 3 & $1.09(0.87-1.35)$ & $0 \%$ & Fixed-effects \\
\hline & High & 2 & $1.53(0.91-2.55)$ & $59.40 \%$ & Random-effects \\
\hline \multirow[t]{4}{*}{ All-cause mortality } & All & 4 & $1.26(0.75-1.21)$ & $83.70 \%$ & Random-effects \\
\hline & Study design & & & & \\
\hline & Cohort & 2 & $1.32(0.49-3.59)$ & $92.70 \%$ & Random-effects \\
\hline & Nested case-control & 2 & $1.23(0.59-2.56)$ & $75.60 \%$ & Random-effects \\
\hline
\end{tabular}
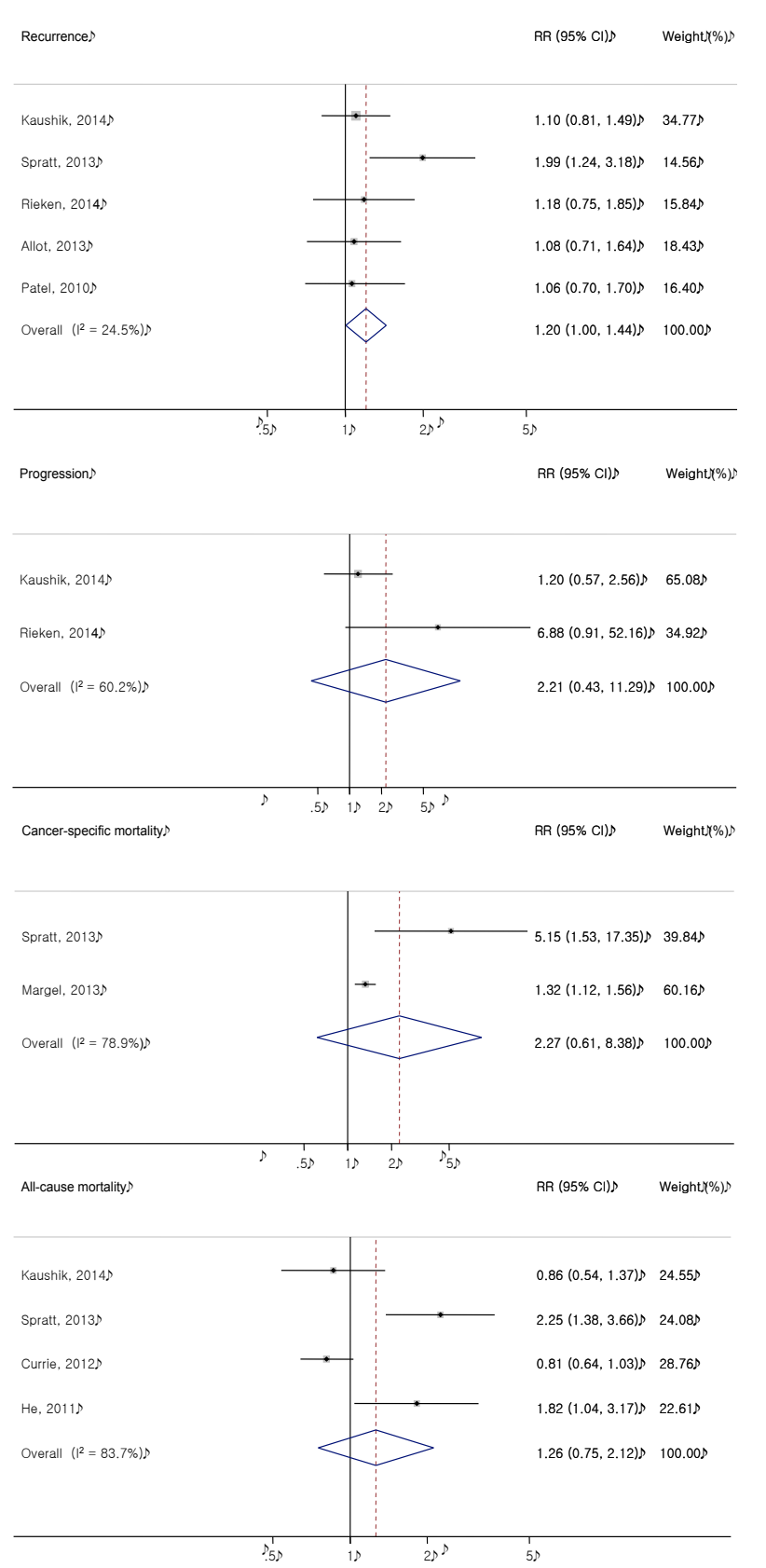

Figure 2. Forest Plot Showing the Relationships between Metformin and Outcomes Associated with Diabetic Prostate Cancer. (A) Recurrence; (B) Progression; (C) Cancer-specific mortality; (D) All-cause mortality. Weights in B-D are from the random-effects model

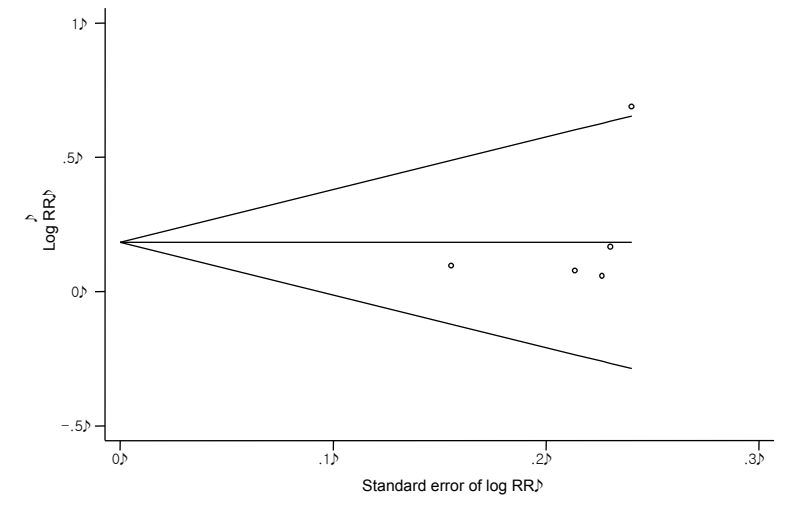

Figure 3. Begg's Funnel Plot with 95\% Confidence Limits for Recurrence among the Included Studies

as demonstrable distant metastasis on radionuclide bone scan or on biopsies outside the prostate (Kaushik et al., 2014). The definition of recurrence was heterogeneous across the studies: biochemical recurrence was defined as a single value of prostate specific antigen (PSA) $\geq 0.2 \mathrm{ng} /$ $\mathrm{mL}$ (Patel et al., 2010; Allott et al., 2013) or $\geq 0.4 \mathrm{ng} / \mathrm{mL}$ (Kaushik et al., 2014), two consecutive concentrations at $0.2 \mathrm{ng} / \mathrm{mL}$ (Allott et al., 2013; Rieken et al., 2014), posttreatment PSA nadir plus $2 \mathrm{ng} / \mathrm{mL}$ (Spratt et al., 2013), or secondary treatment for detectable postoperative PSA (Allott et al., 2013) (not shown in table).

\section{Meta-analysis}

Compared with prostate cancer patients with T2D who used metformin, those who did not use metformin were at increased risk of recurrence (RR, 1.20; 95\%CI, 1.00-1.44; Figure 2A). A similar trend was observed for other outcomes (cancer progression, CSM, and ACM), but these relationships did not reach statistical significance (Figure 2B-D).

Results of subgroup analysis of study design and quality of study on recurrence and ACM among diabetic PCa patients are presented in Table 3; none of the factors analyzed showed significantly different results between subgroups. Further sub-analysis by disease aggressiveness (Gleason score or PSA level) or country could not be conducted due to the small study size. Funnel plot asymmetry was not observed among studies reporting recurrence $(\mathrm{p}=0.086)$ (Figure 3$)$. 


\section{Discussion}

In this study, we conducted a systematic review to summarize research on the effect of metformin use on various PCa outcomes in patients with T2D. Our metaanalysis revealed that metformin use is associated with a decreased risk of recurrence $(20 \%)$ in PCa patients with concurrent T2D. In contrast to the most recent metaanalysis (Zhang and Li, 2014) on PCa mortality, we used only the relevant fully adjusted risk estimates but could not find any significance as well.

Previous studies have described the biological links between pre-existing diabetes and PCa progression, notably the insulin/insulin-like growth factor (IGF) pathway (Sciacca et al., 2013). Insulin appears to be a growth factor for prostatic epithelial cells (Peehl and Stamey, 1986). In addition, IGF-1 and IGF binding protein-3 are associated with prostate growth (Sarma et al., 2002). Potential mechanisms for poor outcomes in PCa patients with T2D include alterations in IGF, its receptors, and their signaling pathways that may result in resistance to treatment (Casa et al., 2008). It is plausible that metformin improves outcomes in PCa by modulating insulin levels.

Our finding that metformin use is not associated with other outcomes may be partly explained by the characteristics of the included studies. For example, Spratt et al. (2013) reported significant effects of metformin on various outcomes. However, unlike some of the studies (limited to M0 or all stages; mean follow up, 2.1-5.1 years) included in our analysis, Spratt et al. limited study participants to those with early stage (limited to N0) cancer and had the longest follow-up duration (mean, 8.7 years). Because PCa tends to be slowly progressive, long-term follow-up is needed to detect some treatment effects. In addition, exposure to metformin in the early stages of cancer appears to improve outcomes.

The comparison group is another important factor in terms of the clinical implications of the results. Several prospective studies of non-diabetic cancer patients have described promising chemopreventive effects of metformin (Bonanni et al., 2012; Niraula et al., 2012) and a potential role for this drug in cancer treatment optimization (Hirsch et al., 2009; Song et al., 2012). On the other hand, using diabetic non-users of metformin as a comparison group may reveal a potential role in the optimal management of concurrent T2D in cancer patients (Landman et al., 2010). A clinical role of metformin in cancer was initially demonstrated in several retrospective studies of patients with T2D patients and various forms of cancer (Currie et al., 2009; Libby et al., 2009); however subsequent studies showed no effect on the long-term, recurrencefree survival rate of patients with T2D (Jiralerspong et al., 2009; Patel et al., 2010). The diabetes-specific nature of these studies prevents generalization to a wider population, because T2D is a strong confounder in cancer outcomes (Snyder et al., 2010). In addition, cancer and T2D share numerous clinical risk factors (e.g., age, sex, obesity, diet, and smoking) and important biological links such as the insulin/IGF signaling pathway (Giovannucci et al., 2010). Limiting our analysis to patients with T2D clarifies the clinical implications of our findings.

Some epidemiological studies demonstrated that metformin is associated with a decreased cancer risk among diabetic patients (Evans et al., 2005; Decensi et al., 2010) and preclinical data also support the concept that metformin exerts anticarcinogenic effects. However, the mechanism underlying this effect remains unclear. It is important to differentiate studies evaluating the ability of metformin to prevent cancer from those evaluating its effects on established tumors. The primary effect of metformin on cancer may be on progression rather than initiation. The role of metformin in cancer prevention may involve the adenosine monophosphate-activated protein kinase pathway (Pollak, 2012), which appears to inhibit cancer progression but not initiation. Metformin diminishes insulin-stimulated neoplastic growth by secondarily decreasing serum insulin levels and inducing autophagy in cancer cells (Ben Sahra et al., 2010). To data, results of studies investigating the relationship between metformin use and PCa risk are still not conclusive (Azvolinsky, 2014).

Our meta-analysis has several limitations. First, our analysis revealed heterogeneity of the included studies in terms of definitions on metformin user and assessed outcomes, especially in recurrence. It is possible that epidemiological biases for both prostate cancer and T2D (i.e., time-related, selection/screening or information) could have affected our findings (Suissa and Azoulay, 2012). Second, most of the included studies were retrospective and missing essential data on lifestyle (smoking and diet), duration of metformin use/T2D, and use of other potential antidiabetic agents (Freedland and Aronson, 2009; Sikka et al., 2012). Duration of diabetes is a good predictor of disease severity, and recurrence risk may increase with a longer duration of T2D (Benoit et al., 2005; Li et al., 2013). Additionally, metabolic derangements including insulin resistance may influence the relationship between metformin use and PCa outcomes (Conteduca et al., 2013). Finally, although we found no evidence of publication bias, inherent bias may exist because small studies with null results are unlikely to be published.

Despite these limitations, our data support the hypothesis that metformin use improves outcomes of diabetic PCa patients and suggest that well-designed prospective trials are warranted to confirm these findings.

\section{Acknowledgement}

This work was supported by National Research Foundation of Korea (NRF) Grant funded by the Korean Government (grant number 2013R1A1A1A05004957) and by the Senior-friendly Product R\&D program funded by the Ministry of Health \& Welfare thorough the Korea Health Industry Development Institute (grant number HI14C1435).

\section{References}

Allott EH, Abern MR, Gerber L, et al (2013). Metformin does not affect risk of biochemical recurrence following radical 
In Cheol Hwang et al prostatectomy: results from the SEARCH database. Prostate Cancer Prostatic Dis, 16, 391-7.

Azvolinsky A (2014). Repurposing to fight cancer: the metformin-prostate cancer connection. J Natl Cancer Inst, 106, dju030.

Bansal D, Bhansali A, Kapil G, et al (2013). Type 2 diabetes and risk of prostate cancer: a meta-analysis of observational studies. Prostate Cancer Prostatic Dis, 16, 151-8.

Begg CB, Mazumdar M (1994). Operating characteristics of a rank correlation test for publication bias. Biometrics, $\mathbf{5 0}$, 1088-101.

Ben Sahra I, Laurent K, Giuliano S, et al (2010). Targeting cancer cell metabolism: the combination of metformin and 2-deoxyglucose induces $\mathrm{p} 53$-dependent apoptosis in prostate cancer cells. Cancer Res, 70, 2465-75.

Ben Sahra I, Laurent K, Loubat A, et al (2008). The antidiabetic drug metformin exerts an antitumoral effect in vitro and in vivo through a decrease of cyclin D1 level. Oncogene, 27, 3576-86.

Benoit SR, Fleming R, Philis-Tsimikas A, Ji M (2005). Predictors of glycemic control among patients with Type 2 diabetes: a longitudinal study. BMC Public Health, 5, 36.

Bonanni B, Puntoni M, Cazzaniga M, et al (2012). Dual effect of metformin on breast cancer proliferation in a randomized presurgical trial. J Clin Oncol, 30, 2593-600.

Casa AJ, Dearth RK, Litzenburger BC, et al (2008). The type I insulin-like growth factor receptor pathway: a key player in cancer therapeutic resistance. Front Biosci, 13, 3273-87.

Conteduca V, Di Lorenzo G, Bozza G, et al (2013). Metabolic syndrome as a peculiar target for management of prostate cancer patients. Clin Genitourin Cancer, 11, 211-20.

Currie CJ, Poole CD, Gale EA (2009). The influence of glucose-lowering therapies on cancer risk in type 2 diabetes. Diabetologia, 52, 1766-77.

Currie CJ, Poole CD, Jenkins-Jones S, et al (2012). Mortality after incident cancer in people with and without type 2 diabetes: impact of metformin on survival. Diabetes Care, 35, 299-304.

Decensi A, Puntoni M, Goodwin P, et al (2010). Metformin and cancer risk in diabetic patients: a systematic review and meta-analysis. Cancer Prev Res (Phila), 3, 1451-61.

DerSimonian R, Laird N (1986). Meta-analysis in clinical trials. Control Clin Trials, 7, 177-88.

Emami Riedmaier A, Fisel P, Nies AT, et al (2013). Metformin and cancer: from the old medicine cabinet to pharmacological pitfalls and prospects. Trends Pharmacol Sci, 34, 126-35.

Evans JM, Donnelly LA, Emslie-Smith AM, et al (2005). Metformin and reduced risk of cancer in diabetic patients. BMJ, 330, 1304-5.

Freedland SJ, Aronson WJ (2009). Dietary intervention strategies to modulate prostate cancer risk and prognosis. Curr Opin Urol, 19, 263-7.

Garcia JA, Danielpour D (2008). Mammalian target of rapamycin inhibition as a therapeutic strategy in the management of urologic malignancies. Mol Cancer Ther, 7, 1347-54.

Giovannucci E, Harlan DM, Archer MC, et al (2010). Diabetes and cancer: a consensus report. CA Cancer J Clin, 60, 207-21.

He XX, Tu SM, Lee MH, Yeung SC (2011). Thiazolidinediones and metformin associated with improved survival of diabetic prostate cancer patients. Ann Oncol, 22, 2640-5.

Higgins JP, Thompson SG (2002). Quantifying heterogeneity in a meta-analysis. Stat Med, 21, 1539-58.

Hirsch HA, Iliopoulos D, Tsichlis PN, Struhl K (2009). Metformin selectively targets cancer stem cells, and acts together with chemotherapy to block tumor growth and prolong remission. Cancer Res, 69, 7507-11.
Jiralerspong S, Palla SL, Giordano SH, et al (2009). Metformin and pathologic complete responses to neoadjuvant chemotherapy in diabetic patients with breast cancer. J Clin Oncol, 27, 3297-302.

Kaushik D, Karnes RJ, Eisenberg MS, et al (2014). Effect of metformin on prostate cancer outcomes after radical prostatectomy. Urol Oncol, 32, 1-7.

Landman GW, Kleefstra N, van Hateren KJ, et al (2010). Metformin associated with lower cancer mortality in type 2 diabetes: ZODIAC-16. Diabetes Care, 33, 322-6.

Li C, Zhao G, Okoro CA, et al (2013). Prevalence of diagnosed cancer according to duration of diagnosed diabetes and current insulin use among U.S. adults with diagnosed diabetes: findings from the 2009 behavioral risk factor surveillance system. Diabetes Care, 36, 1569-76.

Libby G, Donnelly LA, Donnan PT, et al (2009). New users of metformin are at low risk of incident cancer: a cohort study among people with type 2 diabetes. Diabetes Care, 32, 1620-5.

Margel D, Urbach DR, Lipscombe LL, et al (2013). Metformin use and all-cause and prostate cancer-specific mortality among men with diabetes. J Clin Oncol, 31, 3069-75.

Niraula S, Dowling RJ, Ennis M, et al (2012). Metformin in early breast cancer: a prospective window of opportunity neoadjuvant study. Breast Cancer Res Treat, 135, 821-30.

Niraula S, Pond G, de Wit R, et al (2013). Influence of concurrent medications on outcomes of men with prostate cancer included in the TAX 327 study. Can Urol Assoc J, 7, 74-81.

Patel T, Hruby G, Badani K, et al (2010). Clinical outcomes after radical prostatectomy in diabetic patients treated with metformin. Urology, 76, 1240-4.

Peehl DM, Stamey TA (1986). Serum-free growth of adult human prostatic epithelial cells. In Vitro Cell Dev Biol, 22, 82-90.

Pollak M (2008). Insulin and insulin-like growth factor signalling in neoplasia. Nat Rev Cancer, 8, 915-28.

Pollak MN (2012). Investigating metformin for cancer prevention and treatment: the end of the beginning. Cancer Discov, 2, 778-90.

Rieken M, Kluth LA, Xylinas E, et al (2014). Association of diabetes mellitus and metformin use with biochemical recurrence in patients treated with radical prostatectomy for prostate cancer. World J Urol, 32, 999-1005.

Sarma AV, Jaffe CA, Schottenfeld D, et al (2002). Insulin-like growth factor-1, insulin-like growth factor binding protein-3, and body mass index: clinical correlates of prostate volume among Black men. Urology, 59, 362-7.

Sciacca L, Vigneri R, Tumminia A, et al (2013). Clinical and molecular mechanisms favoring cancer initiation and progression in diabetic patients. Nutr Metab Cardiovasc Dis, 23, 808-15.

Sikka S, Chen L, Sethi G, Kumar AP (2012). Targeting PPARgamma signaling cascade for the prevention and treatment of prostate cancer. PPAR Res, 2012, 968040.

Snyder CF, Stein KB, Barone BB, et al (2010). Does pre-existing diabetes affect prostate cancer prognosis? a systematic review. Prostate Cancer Prostatic Dis, 13, 58-64.

Song CW, Lee H, Dings RP, et al (2012). Metformin kills and radiosensitizes cancer cells and preferentially kills cancer stem cells. Sci Rep, 2, 362.

Spratt DE, Zhang C, Zumsteg ZS, et al (2013). Metformin and prostate cancer: reduced development of castration-resistant disease and prostate cancer mortality. Eur Urol, 63, 709-16.

Stroup DF, Berlin JA, Morton SC, et al (2000). Meta-analysis of observational studies in epidemiology: a proposal for reporting. meta-analysis of observational studies in epidemiology (MOOSE) group. JAMA, 283, 2008-12.

Suissa S, Azoulay L (2012). Metformin and the risk of cancer: 